Session 2793

\title{
A Plan to Increase Graduate Enrollment at Science, Mathematics and Engineering Disciplines
}

\author{
Lourdes Sánchez-Contreras, Mehdi Shadaram \\ The University of Texas at El Paso
}

\begin{abstract}
The number of science, engineering, and mathematics (SEM) students who have attended graduate school has dropped considerably over the past few years. The graduate enrollment at both Colleges of Science and Engineering at the University of Texas at El Paso (UTEP) has decreased steadily by about 30\% from 1993-1997. The drop in the College of Engineering is due to the aggressive recruiting by corporations who are offering financially rewarding jobs. While graduates in the College of Science are for most part committed to pursuing post baccalaureate degrees, undergraduate enrollment rates remain low. Meantime, Biology graduates frequently enter into medicine or veterinary school.
\end{abstract}

\section{Introduction}

A plan initiated by the UTEP Model Institution for Excellence (MIE) is under development to increase the percentage of SEM graduates who enroll in graduate school. The main objectives of this task force are to identify and recruit cohorts of junior students who have the potential and desire to pursue careers in research and development, and to promote summer external research activities among SEM undergraduates. Each participating student in the cohort will receive a research stipend for up to two academic years. The Research Experience for Undergraduates (REU), a task force within MIE will assemble student cohorts prior to the fall semester of each year. Each cohort will be divided into Affinity Research Groups. Undergraduate students along with graduate students in each group will participate in carrying out a specific research project supervised by several faculty mentors. The faculty mentors will receive proper training in order to optimize the transition from undergraduate to graduate school. Currently, two Affinity Groups in Computer Science Department with more than 25 students and two Affinity Groups in the Electrical and Computer Engineering Department with more than 20 students have been established. The average percentage of undergraduates in these groups who have pursued graduate degree after graduation is about $45 \%$. Our goal is to establish at least one Affinity Group in each department in the Colleges of Science and Engineering.

Aside from performing research, students in each group will be enrolled in a research seminar each semester, and can earn a total of three academic credits. A faculty and a student coordinator with an active learning format will conduct the seminar. Through the seminar class students will learn to develop research portfolios, computer-aided 
presentations, and showcase web sites. Students will also have an opportunity to prepare and practice for the GRE exam.

The REU coordinator is responsible for securing external summer research opportunities for undergraduates. In order to prevent anxiety and isolationism faculty mentors play a significant role in the placement process of their respective affinity groups.

\section{Implementation}

Until recent semesters the REU program began to concentrate specifically on Science, Math, and Engineering disciplines making this program become more competitive. The purpose and primary goal is to create a pipeline to graduate school for math, science, and engineering students. As a result, faculty members have become more involved in mentoring students. The REU student coordinator is available to assess student's needs. Each semester the number of students who apply and get selected for research opportunities has increased. During the first three years of the program, the number of students who were funded by this program ranged from fifteen to twenty one. In 19981999 there was a major increase in students interested in participating in the MIE program. One of the reasons has been the student awareness that the REU coordinator provides for the students. Visiting student's classrooms and disseminating information has been a very successful mechanism. In summer and fall semesters, the number of students applying ranged from forty-two to eighty students. Since then, more than forty students participate in a research experience.

Below (Fig.1) is a graph indicating the number of students who have participated in the MIE undergraduate research program over five year's period.

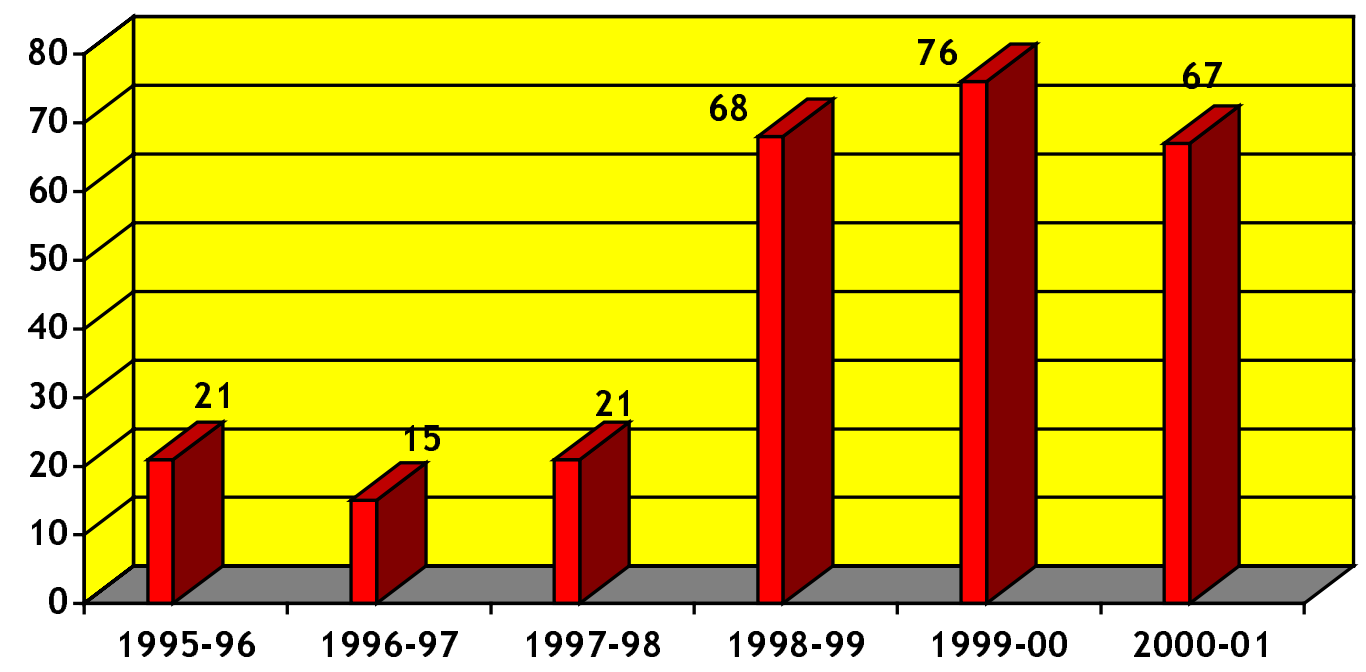

Figure 1. Number of students that have participated over the five-year's period 
Currently, students who are doing research receive information through workshops, e-mail, and flyers about other research opportunities that are available. The REU coordinator also disseminates information on conferences that can give students the opportunity to showcase their research work. Students are highly encouraged to attend informational workshops provided by the MIE-REU program about summer research programs, GRE, resume writing, and graduate opportunities at other universities and research laboratories

In summer of 1999, there were one hundred six students who participated in some type of on-campus research supported either by MIE or other programs. Students also participated in off-campus research during summer 1999. Forty-six students were involved in both a co-op or internship program and seventy-nine participated in research programs where six of them were MIE students.

During the fall 1999 semester, a total of eighty students applied for the MIE research program. Forty-four students were funded and participated in on campus research. In the selection process, usually a committee, made up of SEM faculty members, tries to select equal number of students from both science and engineering disciplines. Below, is a breakdown of the students who participated in undergraduate research for the 1999-2000 academic school year:

Fall 1999

\begin{tabular}{|c|c|c|c|}
\hline Science & $\mathbf{N}$ & Engineering & $\mathbf{N}$ \\
\hline Math & 2 & Civil Engineering & 3 \\
\hline Biology & 2 & Computer Science & 3 \\
\hline Chemistry & 2 & Computer Engineering & 1 \\
\hline Geology & 6 & Electrical Engineering & 4 \\
\hline Microbiology & 8 & Industrial Engineering & 6 \\
\hline Physics & 2 & Mechanical Engineering & 3 \\
\hline & & Metallurgy & 2 \\
\hline
\end{tabular}

Spring 2000

\begin{tabular}{|c|c|c|c|}
\hline Science & $\mathbf{N}$ & Engineering & $\mathbf{N}$ \\
\hline Math & 2 & Civil Engineering & 3 \\
\hline Biology & 8 & Computer Science & 3 \\
\hline Chemistry & 2 & Computer Engineering & 1 \\
\hline Geology & 3 & Electrical Engineering & 5 \\
\hline Microbiology & 6 & Industrial Engineering & 2 \\
\hline \multirow[t]{2}{*}{ Physics } & 2 & Mechanical Engineering & 6 \\
\hline & & Metallurgy & 3 \\
\hline
\end{tabular}


During fall 2000 semester, there were fifty-two students doing research under the REU program. Below is the breakdown:

Fall 2000

\begin{tabular}{|l|l|l|l|}
\multicolumn{1}{c|}{ Science } & N & \multicolumn{1}{c}{ Engineering } & N \\
\hline Math & 0 & Civil Engineering & 6 \\
\hline Biology & 7 & Computer Science & 1 \\
\hline Chemistry & 1 & Metallurgy & 3 \\
\hline Geology & 2 & Electrical Engineering & 11 \\
\hline Microbiology & 9 & Industrial Engineering & 5 \\
\hline Physics & 3 & Mechanical Engineering & 4 \\
\hline \multicolumn{2}{|c|}{ Total: Total: } & 30 \\
\hline
\end{tabular}

Currently, there are fifty three students participating in the MIE-REU program. Below is the breakdown:

\section{Spring 2001}

\begin{tabular}{|l|l|l|l|}
\multicolumn{1}{r}{ Science } & N & \multicolumn{1}{c}{ Engineering } & N \\
\hline Math & 1 & Civil Engineering & 2 \\
\hline Biology & 10 & Computer Science & 1 \\
\hline Chemistry & 3 & Metallurgy & 2 \\
\hline Geology & 1 & Electrical Engineering & 11 \\
\hline Microbiology & 12 & Industrial Engineering & 1 \\
\hline Physics & 4 & Mechanical Engineering & 5 \\
\hline \multicolumn{2}{|r|}{ Total: } & 31 \\
\hline
\end{tabular}

Among our goals previously mentioned, is for students to participate in external research programs and other activities such as: Research Expositions, the Geological Society of America Conference, the Computational Neuroscience Symposiums, the Joint Mathematics Meetings, and the MIE Annual Conference

Another benefit of this program has been securing research positions with other universities and/or research sites. Students have the opportunity to participate in an external research experience during the summer session. During the regular school semesters, a student coordinator makes arrangements to secure research slots for students. Currently slots are being secured with Sandia National Laboratories, University of Michigan, University of Wisconsin Madison, University of Nebraska-Lincoln, California Technology Institute among many others. This summer, it is expected for at least $40 \%$ of the students in the REU program to participate in some type of summer research experience. 
Below (Fig. 2) is a map to show some of the universities and research sites that have funded and offered UTEP students an external research experience.

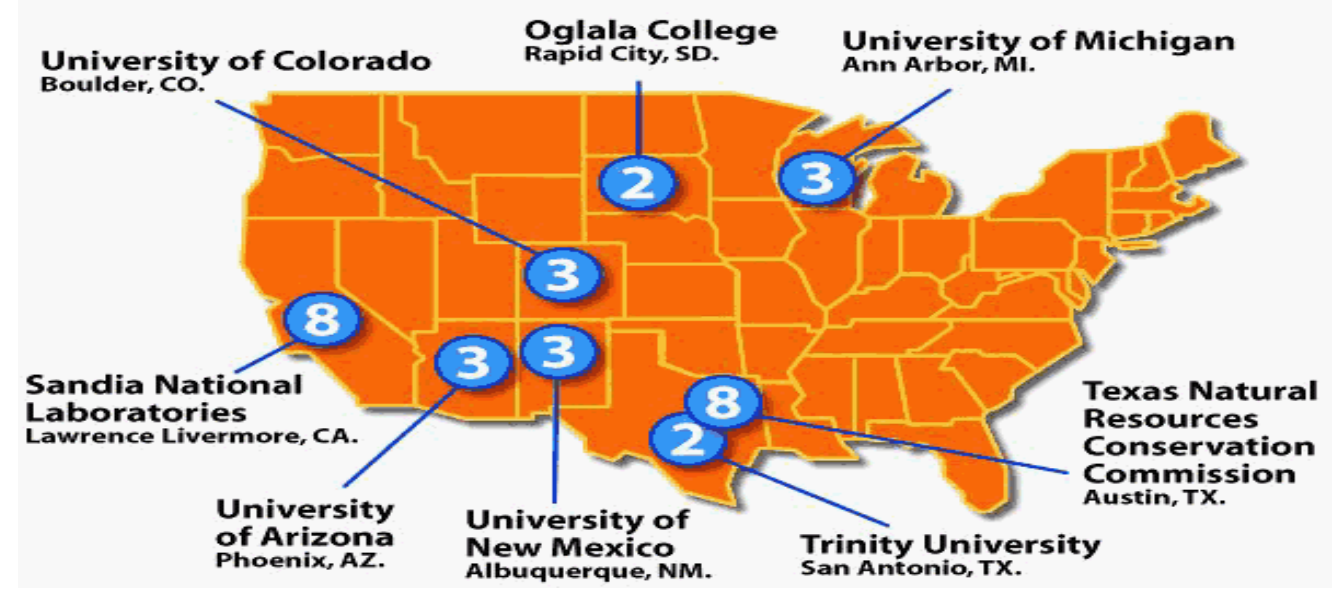

Fig.2 Number of External Research Opportunities for Summer 2000

\section{Conclusion}

In summary, the Affinity Research Group concept and the previously mentioned model [1] provide an innovative way of structuring research groups that involve undergraduate and graduate students. Built on a cooperative model, affinity research groups include students with a wide range of experiences and skill levels, and provide them with opportunities to deepen their knowledge in technical areas. Through structured and welldefined components, students develop technical, research, and professional skills that are need to become effective leaders and make significant research contributions.

We are planning to refine this program over a three-year period starting fall semester of 2001. By the end of period, one student cohort will be in graduate school for a year and its performance will be assessed. After the first three-year period, each year one cohort will be ready to enter graduate school and two cohorts will be in the pipeline.

Bibliography:

[1] Gates, A.Q., Teller, P.J., Bernat, A., Delgado N., and Kubo

Della-Piana, C., "Expanding Participation in Undergraduate Research Using the Affinity Group Model," Journal of Engineering Education, Vol. 88, No. 4, October 1999. 


\section{MEHDI SHADARAM}

Professor Mehdi Shadaram was born on April 19, 1954. He received a B.S.E.E. degree from the University of Science and Technology in Tehran in 1976, M.S. and Ph.D. degrees from the University of Oklahoma, both in electrical engineering, in 1980 and 1984 respectively.

He came to The University of Texas at El Paso (UTEP) in 1984 as an Assistant Professor in the Electrical and Computer Engineering Department and was promoted to full Professor in 1997. In January 1999 he became the director of Undergraduate Research Programs at UTEP, and since August 1999 he has served as the Chairman of his department. Prior to his UTEP assignment, he worked as Project Engineer at RaNav Laboratories in Oklahoma City for a period of two years. His research activities at UTEP are focused on the field of optical fibers and photonics. NASA, Jet Propulsion Laboratory, National Science Foundation, Office of Naval Research, Department of Defense, Nortel, and Lucent Technologies have funded his research projects. He has published more than sixty articles all in his area of research, most of them in refereed journals and conference proceedings.

Dr. Shadaram is a registered Professional Engineer (P.E.) in the State of Texas. He is cited in the Marquis Who's Who in the World and Who's Who in Science and Engineering. He is a senior member of IEEE, member of the International Society for Optical Engineering, Optical Society of America, and Eta Kappa Nu. He has received the Associated Western Universities Faculty Fellowship Award in 1990 and 1991, ASEE-Navy Summer Faculty Fellowship Award (1994-1998), and was recognized for advising the best thesis at UTEP in 1989. He is the recipient of C.R. Nichols Award in 1993 for teaching excellence at the Electrical and Computer Engineering Department of UTEP. In the past, he has served as IEEE Chairman and Treasurer of El Paso Section, and IEEE Faculty Advisor of UTEP Student Chapter.

\section{LOURDES SANCHEZ-CONTRERAS}

Lourdes Sanchez - Contreras is a coordinator for the Research Experience (REU) for Undergraduates program under the Model Institutions for Excellence at the University of Texas at El Paso. She is actively involved in working with undergraduate research students. Her main objective is to involve and make students aware of the educational opportunities that exist in research at other universities and research laboratories. She is also in charge of securing summer research positions for UTEP students at other universities and research sites. She received a B.A. in Chicano Studies in 1998 and a second B.A. in Sociology in 1999 from the University of Texas at El Paso. She is currently a master's student in the Public Administration Program. 